\title{
Dutch guidelines for physiotherapy in patients with stress urinary incontinence: an update
}

\author{
Arnold T. M. Bernards • Bary C. M. Berghmans • \\ Marijke C. Ph. Slieker-ten Hove • J. Bart Staal • \\ Rob A. de Bie • Erik J. M. Hendriks
}

Received: 16 May 2013 / Accepted: 27 August 2013/Published online: 1 October 2013

(C) The Author(s) 2013. This article is published with open access at Springerlink.com

\begin{abstract}
Introduction and hypothesis Stress urinary incontinence (SUI) is the most common form of incontinence impacting on quality of life (QOL) and is associated with high financial, social, and emotional costs. The purpose of this study was to provide an update existing Dutch evidence-based clinical practice guidelines (CPGs) for physiotherapy management of patients with stress urinary incontinence (SUI) in order to support physiotherapists in decision making and improving efficacy and uniformity of care.

Materials and methods A computerized literature search of relevant databases was performed to search for information regarding etiology, prognosis, and physiotherapy assessment and management in patients with SUI. Where no evidence
\end{abstract}

\author{
A. T. M. Bernards • B. C. M. Berghmans • R. A. de Bie • \\ E. J. M. Hendriks \\ Department of Epidemiology and Centre for Evidence Based \\ Physiotherapy \& Clinical Guidelines (CEBP), Maastricht University, \\ Maastricht, The Netherlands \\ B. C. M. Berghmans \\ e-mail: bary.berghmans@maastrichtuniversity.nl \\ R. A. de Bie \\ e-mail: ra.debie@maastrichtuniversity.nl \\ E. J. M. Hendriks \\ e-mail: erik.hendriks@maastrichtuniversity.nl
}

A. T. M. Bernards $\cdot$ J. B. Staal

Centre for Musculoskeletal Rehabilitation, HAN University of

Applied Sciences, Nijmegen, The Netherlands

J. B. Staal

e-mail: b.staal@iq.umcn.nl

A. T. M. Bernards $(\triangle)$

Department of Research and Development, Dutch Institute for Allied

Health Care (NPI), Amersfoort, The Netherlands

e-mail: Nol.Bernards@han.nl was available, recommendations were based on consensus. Clinical application of CPGs and feasibility were reviewed. The diagnostic process consists of systematic history taking and physical examination supported by reliable and valid assessment tools to determine physiological potential for recovery. Therapy is related to different problem categories. SUI treatment is generally based on pelvic floor muscle exercises combined with patient education and counseling. An important strategy is to reduce prevalent SUI by reducing influencing risk factors.

Results Scientific evidence supporting assessment and management of SUI is strong.

Conclusions The CPGs reflect the current state of knowledge of effective and tailor-made intervention in SUI patients.
B. C. M. Berghmans

Pelvic care Center Maastricht (PcCM), Maastricht University

Medical Centre, Maastricht, The Netherlands

M. C. Ph. Slieker-ten Hove

Department of Obstetrics and Gynaecology, Department

Physiotherapy, Erasmus, University Medical Centre, Rotterdam,

The Netherlands

e-mail: m.slieker-tenhove@erasmusmc.nl

M. C. Ph. Slieker-ten Hove

ProFundum Institute, Dordrecht, The Netherlands

J. B. Staal

Scientific Institute for Quality of Healthcare (IQ Healthcare),

Radboud University Medical Centre, Nijmegen, The Netherlands

R. A. de Bie $\cdot$ E. J. M. Hendriks

School for Public Health and Primary Care (CAHPRI),

Maastricht University, Maastricht, The Netherlands 
Keywords Diagnostic process · Evidence $\cdot$ Guideline · Physiotherapy · Therapeutic process $\cdot$ Stress urinary incontinence $\cdot 3 \mathrm{IQ} \cdot$ Incontinence Questionnaire

\begin{tabular}{|c|c|}
\hline \multicolumn{2}{|c|}{ Abbreviations } \\
\hline BMI & Body mass index \\
\hline CPGs & Clinical practice guidelines \\
\hline COPD & Chronic obstructive pulmonary disease \\
\hline EBRO & Evidence- Based Richtkijn (Guideline) \\
\hline & Ontwikkeling (Development) \\
\hline GPE & $\begin{array}{l}\text { Global Perceived Effect scale (measurement } \\
\text { instrument) }\end{array}$ \\
\hline ICF & $\begin{array}{l}\text { International Classification of Functioning, } \\
\text { Disability and Health }\end{array}$ \\
\hline PFM & Pelvic floor muscles \\
\hline PFMT & Pelvic floor muscles training \\
\hline PRAFAB & $\begin{array}{l}\text { Protection, Amount, Frequency, Adjustment } \\
\text { Body Image (measurement instrument) }\end{array}$ \\
\hline PSC & $\begin{array}{l}\text { Patient-Specific Complaints (measurement } \\
\text { instrument) }\end{array}$ \\
\hline SUI & Stress urinary incontinence \\
\hline UI & Urinary incontinence \\
\hline $\mathrm{VC}$ & Vaginal cones \\
\hline
\end{tabular}

\section{Introduction}

Stress urinary incontinence (SUI) is the most common form of urinary incontinence (UI) [1, 2]. It often severely impacts on quality of life (QOL) [3] and is associated with high financial, social, and emotional costs $[4,5]$. This article is based on an updated, state-of-the-art, evidence-based physical therapy guideline [6] and gives extra attention to the following topics: definition of SUI, the biopsychosocial model, SUI etiology, and prognostic factors that may predict physiotherapy success. Definitions are according to the International Continence Society (ICS) and the International Urogynecological Association (IUGA) [7]. The guidelines involve diagnosis and treatment of adult patients with (predominant) SUI.

The biopsychosocial model assumes that SUI involves a decrease in resilience of the pelvic floor that may lead to impairments in physical and mental functioning, restrictions in activities, and in participation [8]. This model addresses the consequences of SUI, taking into account prognostic factors that may influence recovery and emphasizing the role of physical, psychological, and social factors in the development and/or persistence of SUI.

The total urethral closing mechanism consists of two combined mechanisms ensuring urinary continence, i.e., an intrinsic urinary sphincteric closure mechanism and an extrinsic urethral- and vaginal-wall support mechanism [9]. The former depends on three different layers in the wall of the urethra-the tunica mucosa, the spongiosa, and the muscularis - whereas the latter depends on the supportive function of the pelvic floor. The major components of this supportive structure are the vaginal wall, the endopelvic fascia, the arcus tendineus fasciae pelvis, and the levator ani muscles [9]. SUI can develop if there is dysfunction in one or both of these mechanisms [10]. Etiological factors of SUI are as follows:

1. Intrinsic (urethral) closure mechanism

- Atrophy of the tunica mucosa and the tunica spongiosa (estrogen deficiency, e.g., postmenopausal)

- Dysfunctional tunica muscularis (e.g., due to surgical interventions such as transurethral prostate resection or radical prostatectomy or trauma)

2. Extrinsic support mechanism

- Weak pelvic floor muscles and ligaments

- Pregnancy

- Vaginal delivery

- Instrumental delivery (vacuum or forceps)

- Episiotomy

- Maternal age at first delivery $\leq 30$ years

- Parity, increasing after three or more deliveries

- Being overweight $[25 \leq$ body mass index $(\mathrm{BMI})<30]$

- Consuming carbonated drinks

- Age

Prognosis for recovery in SUI depends on the nature of the underlying disorder and/or disease process. Prognostic factors for reduced chance of spontaneous recovery and recovery after physiotherapy were identified through prospective cohort studies.

1. Reduced chance of recovery

- Increasing severity of the SUI

- Previous conservative treatment for SUI with an unfavorable outcome

- SUI during pregnancy and during the first 3 months after delivery

- Number of pregnancies

- Prolonged second stage of labor

- Severe prolapse [Pelvic Organ Prolapse Quantification system (POP-Q) stage 3 or 4]

- Being overweight

- Presence of other diseases or disorders, such as chronic obstructive pulmonary disease (COPD) and cardiovascular diseases

- Psychological strain

- Patient-perceived low physical condition 
2. Increased chance of recovery

- Higher educational level

- Higher level of motivation for and adherence to a pelvic floor training program

\section{Literature search}

For the period 1998 to September 2012, the following databases were searched: PubMed, MEDLINE, Embase, CINAHL, PEDro, and the Cochrane Database, for publications on SUI nature, severity, physiotherapeutic diagnostic procedures, and preventive and therapeutic interventions. Additional tracking of further relevant publications was performed. Methodological quality of individual studies was graded following the criteria for Evidence-Based Guideline Development (EBRO) criteria [11] in order to formulate recommendations for the guideline and assess the quality of the other aspects - in addition to scientific evidence - that are important for formulating recommendations, such as achieving general consensus, efficiency (costs), resource availability, required therapist expertise and training, organizational aspects, and efforts to harmonize the guidelines with other monodisciplinary or multidisciplinary guidelines. The methodology used to formulate its recommendations is presented in Table 1.

\section{Establishment of consensus}

If no scientific research was available to guide clinical reasoning, recommendations were made based on established consensus. Clinical experts in the development team had to make their clinical reasoning explicit, explain their clinical expertise, and explain which concepts and ideas were used in their clinical reasoning. Recommendations were subsequently based on consensus that was established after discussion within the development team of the concepts used. Biological/physiological plausibility was a guiding principle. A summary of the recommendations is presented at the end of the article.

\section{Diagnostic process}

The diagnostic process is based on systematic reviews [12] and other relevant Dutch guidelines [13]. During this process, which is used to formulate a specific treatment plan, the nature of the underlying disorder and SUI severity (assessed on the basis of the ICF [8]) are examined in the context of whether the underlying disorders and/or any identified unfavorable prognostic factors are modifiable by physiotherapy. Goaloriented and systematic history taking involved medical, paramedical, communicative, and attitudinal aspects. Type of incontinence, estimation of volume of urine loss, impact, and identification of any underlying disorder and factors

Table 1 Levels of evidence: classification of methodological quality of individual studies

\begin{tabular}{|c|c|c|}
\hline Intervention & Diagnostic accuracy of study & Harm/side-effects, etiology, prognosis ${ }^{\mathrm{a}}$ \\
\hline \multicolumn{3}{|l|}{$\begin{array}{l}\text { A1: Systematic review of at least two } \\
\text { independent A2-level studies }\end{array}$} \\
\hline $\begin{array}{l}\text { A2: Randomized, double-blind, } \\
\text { comparative clinical trial of good } \\
\text { quality and sufficient sample size }\end{array}$ & $\begin{array}{l}\text { Study compared with a reference test } \\
\text { (gold standard) with predefined cutoff } \\
\text { values and independent assessment of } \\
\text { outcomes of the test and the gold standard, } \\
\text { based on a sufficiently large sample of } \\
\text { consecutive patients, all of whom have } \\
\text { undergone the index and reference tests }\end{array}$ & $\begin{array}{l}\text { Prospective cohort study with sufficient sample } \\
\text { size and follow-up, effectively controlled for } \\
\text { confounding and with effective measures to } \\
\text { prevent selective follow-up }\end{array}$ \\
\hline $\begin{array}{l}\text { B: Comparative study not meeting } \\
\text { all criteria mentioned under A2 }\end{array}$ & $\begin{array}{l}\text { Study compared with a reference test, not } \\
\text { meeting all criteria mentioned under A2 }\end{array}$ & $\begin{array}{l}\text { Prospective cohort study not meeting all criteria } \\
\text { mentioned under A2, or retrospective cohort study }\end{array}$ \\
\hline \multicolumn{3}{|l|}{ C: Noncomparative study } \\
\hline \multicolumn{3}{|l|}{ D: Expert opinion } \\
\hline \multicolumn{3}{|l|}{ Level of conclusions. } \\
\hline Conclusion based on: & & Recommendations based on conclusion level: \\
\hline $\begin{array}{l}\text { 1. Study at A1 level or at least two } \\
\text { independent A2-level studies }\end{array}$ & & It has been demonstrated that... \\
\hline $\begin{array}{l}\text { 2. One study at A2 level or at least } \\
\text { two independent B-level studies }\end{array}$ & & It is plausible that... \\
\hline 3: One B- or C-level study & & There are indications that... \\
\hline 4. Expert opinion & & In the opinion of the guideline development team, \\
\hline
\end{tabular}

${ }^{a}$ This classification is only relevant for situations in which controlled trials are impossible due to ethical or other considerations. If controlled trials are an option, the classification for interventions is to be used 
contributing to incontinence (e.g., use of medication and alcohol, abnormal fluid intake, limitations, and comorbidity) are assessed. UI description in relation to precipitating factors, social impact, effect on hygiene and QOL, measures taken to control UI, and the patient's illness beliefs are assessed [12]. In addition, particularly in primary care, the Incontinence Questionnaire (3IQ) test is useful for assessment of type of UI [14]. The severity of the patient's health problem is assessed by using the ICF, determining frequency and UI volume, use of absorptive products, and impact of UI on everyday life, including work, sports, housekeeping activities, family life, social life, and sexuality. Illness beliefs can have a favorable or adverse effect on the prognosis in terms of recovery and should be identified because beliefs may partly determine the type of intervention that can be used and can affect expectations of both the patient and the physiotherapist [15]. Physical examination includes inspection at rest and during movement, vaginal and/or rectal palpation, and functional examination, assessing:

- Level of voluntary and involuntary control of the pelvic floor, coordination of the pelvic floor muscles (PFM), and synergistic activity

- Quantification and symmetry of (in)voluntary PFM contraction and relaxation

- Other PFM functions, such as endurance, fatigue

- Whether and to what extent other aspects of the musculoskeletal system, such as respiration, lower back, pelvis, and hip, are hampering PFM function

- Any local and other (i.e., general) unfavorable prognostic factors

Physical examination provides information about whether an inward movement is visible/palpable on contraction, whether any cocontraction and relaxation is visible/palpable, and whether movement of the perineum is visible on coughing and straining [16]. Vaginal or rectal palpation enables the therapist to evaluate the correct performance of PFM contraction and relaxation [16]. The contraction may be categorized as being absent, weak, normal, or strong. Relaxation can be rated as absent, partial, or complete [17]. Assessment of PFM tonicity is hampered by the fact that there are as yet no generally accepted definitions for the terms normal tonus, hypertonus, and hypotonus [17]. The ICS Pelvic Floor Clinical Assessment Group has opted for a summary description as being a condition: PFM could therefore be normal, overactive, underactive, or nonfunctioning [17]. To evaluate PFM function, use of the following assessment schedule, described in the practice guidelines, is recommended:

- Assess whether the patient is able to voluntarily contract and relax the PFM, and evaluating the performance

- Assess the effectiveness of voluntary contraction and relaxation of the PFM
- Assess the effectiveness of involuntary contraction of the PFM associated with a sudden increase in intra-abdominal pressure (forceful coughing) and subsequently during coughing after the patient has been instructed to contract their pelvic floor first

- Assess the effectiveness of involuntary relaxation of the PFM during straining

- Observe the voluntary contraction and relaxation of the PFM in relation to the abdominal muscles

- Establish any differences between the right and left sides while the patient contracts and relaxes the PFM

- Quantify the strength, endurance, and explosive strength of the PFM

In healthy individuals, intra-abdominal pressure is automatically regulated by feed-forward control of the transversus abdominis muscle, with the diaphragm and the PFM [18-20]. A strong relationship is described between lower back pain on the one hand and incontinence and respiratory dysfunction on the other as the consequence of a limited ability to sufficiently integrate trunk muscle function in the regulation of posture and respiration as well as continence [21]. Good voiding posture and relaxed pelvic floor and breathing create optimal conditions for voiding the bladder and intestines [22]. The therapist should inspect the following (level 3) [21, 23]:

- Patient's sitting and standing posture (urethral angle, anorectal angle, abdominal pressure, and toileting behavior)

- Respiration (breath holding and vocal behavior)

- Movements (mobility and tonicity of the spinal column, abdominal, and pelvic regions and movement patterns)

- Abdominal, buttock, and leg muscles (patients with fatigued PFM often show increased activity of other muscles)

Local resilience can be reduced as a result of rupture or incisional scars by anterior or posterior vaginal wall defects or by uterine prolapse. Inspection can be used to identify signs of reduced pelvic floor resilience. The patient's specific resilience can be estimated from her general physical condition. Obesity is an unfavorable prognostic factor for recovery (level 3) [24] and can be assessed using BMI measurement [24].

\section{Measurement instruments}

UI severity and consequences for everyday life, patient's adjustment to the problem and significance for the patient's sense of self-esteem, and physiotherapeutic effect changes are measured and evaluated. The Protection, Amount, Frequency, Adjustment Body Image (PRAFAB) questionnaire measures UI severity in terms of use of absorptive products (PRotection), volume (Amount), and occurrences (Frequency) (leakage severity scale), impact 
in terms of patient adjustment to UI in everyday life (Adjustment), and consequences for patient's self-image (Body image) (perceived impact scale) [25].. It can be used to record changes in individual health status (level 2) [26]. UI can be quantified by weighing incontinence pads used after a specified period of time. A 24-h pad test is a reliable instrument for assessing UI loss (level 2) [12, 27]. The Patient-Specific Complaints (PSC) instrument enables the patient to indicate the main activities in which they feel restricted and helps the physiotherapist determine the patient's subjective functional status before and after treatment, making the instrument suitable for (effect) evaluation [28]. The Global Perceived Effect (GPE) scale indicates the patient's general perception of subjective health status improvement (level 2) [29, 30]. On a 3-day micturition diary, UI severity, i.e., number of incontinent episodes and result of treatment, is assessed (level 1) [31]. The diary can also be used to give specific feedback and advice to the patient on the timing of eating/drinking, micturition, and toileting behavior [22, 32].

Analysis of all gathered data involves the explicit decision as to whether physiotherapy is indicated. For modifiable prognostic factors, explicit physiotherapeutic goals are formulated [33]. Based on the analysis, a number of problem categories can be distinguished:

\section{SUI with PFM dysfunction:}

- The patient is unable to identify their PFM, has no awareness, cannot manage contraction or relaxation, shows no effective involuntary contraction of the PFM associated with increased abdominal pressure

- The patient is unable to identify their PFM, has no awareness, cannot manage contraction or relaxation, shows some involuntary contraction of the PFM associated with increased abdominal pressure, but contraction is ineffective

- The patient is unable to identify their PFM, has no awareness, cannot manage contraction or relaxation, but shows effective involuntary contraction of the PFM associated with increased abdominal pressure

- The tone of the PFM is measurably too high, and the patient is unable to reduce this on demand (with or without voluntary tightening and with or without effective involuntary contraction associated with increased abdominal pressure)

- The patient is able to tighten and relax the PFM but has no effective involuntary control over the PFM associated with increased abdominal pressure

- The patient has both voluntary and involuntary control over the PFM, but the PFM are too weak

- The functioning of other parts of the musculoskeletal system, e.g., in relation to respiration, voiding posture, and toileting behavior, adversely affects PFM function
SUI without PFM dysfunction:

- SUI plus local and/or other (general) unfavorable prognostic factors that may have adverse local or general effects on recovery and/or adjustment processes, and which may or may not be modifiable by physical therapy interventions

\section{Treatment plan}

Depending on the modifiability of the SUI condition, objectives of physiotherapy are defined. PFM training (PFMT) should aim not only to increase the physical condition of the pelvic floor, but also to maintain it (use it or lose it). This requires permanent active involvement and changes to the patient's lifestyle. Physiotherapy needs to support this behavioral change. In addition, the patient's general physical condition must be optimized in order to reduce the influence of other diseases and/or disorders on the continence mechanism. First, information and explanation about the nature of the patient's problem is given. Patients are more motivated to start the therapy if they understand normal anatomy and physiology, the influence of (mental) stress and relaxation on PFM functioning, and the causes and development of SUI [34]. This type of patient-specific education must be a standard treatment plan component.

\section{Therapeutic process}

Therapeutic interventions aim to:

1. Provide information and advice. This includes explanation about risk and prognostic factors in general and specific to the patient, lifestyle advice, and the use of anatomical diagrams and pelvic models (level 4).

2. Improve general physical condition. UI risk decreases with increasing level of moderate physical activity [35, 36] (level 3).

3. Improve functional condition of the pelvic floor:

(a) PFM training to enable voluntary contraction and relaxation, increase strength and endurance, and promote involuntary contraction to support increase in intra-abdominal pressure.

The goal of PFM training is to improve the extrinsic support mechanism to such an extent that the pelvic floor provides enough support to prevent UI loss associated with increased intra-abdominal pressure [37, 38]. Supervised and intensive PFMT results in complete recovery or at least considerable improvement in 60 $70 \%$ of women with SUI (level 1) and to a reduction in 
subjective symptoms (level 1). This improvement can be objectively confirmed by urodynamic examination and a pad test (level 1). PFMT also results in objective improvement of the PFM function (level 1) and in the patient's QOL (level 1). There are no adverse or side effects (level 1). Its success rate can be improved by checking whether patients carry out PFME correctly (level 1) [39] and that teaching women with SUI to contract their PFM just before and during an increase in intra-abdominal pressure is an effective treatment method (level 1) [37].

The training program should be designed to be realistically feasible in order to promote compliance. It must be possible to integrate the exercises into everyday activities. PFMT effect is partly determined by training frequency and duration of the training period (level 2) [40, 41]. Daily PFMT with sufficient intensity and duration is recommended [39] while paying attention to the correct performance and ultimately - integration into daily life activities of the exercises (level 4).

Prognostic factors such as patient's physical fitness, whether overweight, and comorbidities such as cardiovascular diseases or COPD have an adverse effect on the development and persistence of SUI, therefore on the effect of PFMT (level 3) [42], and should, if modifiable, be incorporated into the intervention strategy.

(b) Biofeedback

Biofeedback uses an external sensor to assess a bodily process, usually with the intention of altering the variable being measured [43]. Biofeedback is not a therapy in itself but can be used combined with PFMT in SUI treatment to indicate PFM activity at rest, on contraction, and in relaxation. Furthermore, it can indicate the strength of individual PFM contractions (electromyogram), strength of the contracting PFM (pressure measurement) or the way in which certain muscles contract, and the direction of contraction (ultrasound). The combination is no more effective than PFMT alone [37, 38, 42, 44, 45]. Both treatment modalities are effective, whereas biofeedback may have added value in SUI patients with insufficient awareness and/or control of the pelvic floor, may speed up initial improvement, and may support motivation to keep exercising (level 4) [46].

(c) Electrical stimulation

The goal of electrical stimulation in the treatment of patients with SUI is to make the PFM contract, with the aim of achieving a training effect to ensure that the pelvic floor will provide sufficient support to prevent UI loss during an increase in intra-abdominal pressure. There is insufficient evidence that electrical stimulation alone is an effective treatment for patients with SUI (level 1), and the addition of electrical stimulation to PFMT offers no additional benefits (level 1) [47, 48].

However, it might be useful to support the initial steps toward a functional training program by providing a better awareness of how to (correctly) contract the PFM in patients with insufficient voluntary control and capacity. This statement needs further research $[38,47]$.

(d) Vaginal cones

The goal of using vaginal cones (VC) is to train the PFM by contracting them to hold a weight inserted into the vagina. If the patient manages to hold a particular weight, it is then replaced by a slightly heavier weight. VC effectiveness compared with no treatment or combined PFMT and electrical stimulation remains unclear (level 1) [38]. On the other hand, combining PFMT with VC in accordance with the general principles of strength training may be effective (level 3) [45]. However, many women find VC training difficult and uncomfortable (level 1) [38].

\section{Preventing SUI}

Continent primigravidae women should be offered a supervised and intensive antepartum strengthening PFMT program to prevent postpartum UI (level 1) $[38,39]$.

\section{Evaluation}

Because the nature and/or severity of the underlying disorder at referral is often unclear, there may be impediments to recovery that cannot be modified by physiotherapy. Therefore, early evaluation after a pilot treatment of six sessions is recommended. Where there has been no progress on the PRAFAB and/or GPE, physiotherapy should be interrupted, referring the patient back for further investigation and/or treatment, such as surgery. As good physical condition of the pelvic floor is a favorable prognostic factor for postoperative recovery after surgical intervention, physiotherapy can be regarded as useful.

\section{Interaction between physiotherapists and other health-care providers}

Most patients will see the physiotherapist through referral by a medical doctor who believes that physiotherapy may 
make an important contribution to reducing the problem. Communication between doctor and physiotherapist about etiology and prognostic factors is necessary. Back referral is necessary if complications arise during the treatment period or when, despite therapy, incontinence severity insufficiently decreases. It is possible that surgery may be an option in such cases. The patient must be referred back to the referring doctor if treatment goals are not met but the physiotherapist estimates that the patient has achieved the maximum possible result. If the patient approaches the physical therapist directly, special agreements are made. If the diagnosis is unclear, the patient should be referred to a medical doctor. For patients who must undergo a prostatectomy, the urologist can ask the physical therapist to teach the patient specific exercises preoperatively and provide instructions for postoperative exercises to implement after catheter removal.

\section{Discussion}

These guidelines, based on state-of-the-art evidence, serve to assist physiotherapists in diagnosing and treating patients with UI. The main benefits of the CPGs are to improve the quality of care, provide uniformity in care, and make physiotherapy more transparent to the referring physician and to patients [ 48 , 49]. Guidelines should be followed, but physiotherapists may deviate from them if there are good reasons to do so. Conclusions of systematic reviews form the main basis for intervention recommendations. Because not all recommended interventions are evidence based, these guidelines may contain some bias [50]. The use of guidelines requires the physiotherapist to be constantly aware of specific patient characteristics and the applicability of evidence-based recommendations. This will help physiotherapists in decision making and in optimising the quality of care.

An important strategy when using these guidelines is to reduce prevalent SUI by reducing the risk and by diminishing the influence of prognostic factors. An early distinction between patients with SUI based on the presence of prognostic factors would allow early selection of patients who need additional treatment and would help to set treatment goals.

Physiotherapists who use these guidelines need to understand the nature of the SUI, the influence of prognostic factors, the available scientific evidence, and the principles of behavioral therapy. Because education and progressive exercises are important components of behavioral therapy, physiotherapists should provide them. By increasing the ability to carry out activities and demonstrating that physical activity is beneficial and may relieve symptoms, physiotherapists may contribute to movement behavior modification and to changes in cognitions about incontinence.
Implementation activities are planned for the future. For useful implementation, the development of effective strategies is of the utmost importance.

\section{Conclusion}

Clinical practice guidelines presented here for physiotherapeutic management of SUI patients have been developed and updated to assist physiotherapists in providing appropriate care. Overall, evidence was strong, although the guidelines also reflect consensus among experts when evidence was lacking. The guidelines reflects the current state of knowledge about effective and appropriate physiotherapeutic care of patients with SUI. Better quality research is needed to validate the consensus-based recommendations.

A summary of recommendations follows:

1. Problem definition

- Identifying etiological factors - the therapist should systematically identify etiological factors in order to assess the nature of the dysfunction of the continence mechanism (level 4)

2. Diagnostic process

- Establishing the type of incontinence - the guideline development team recommends using the 3IQ test to establish the type of incontinence (level 1)

- Palpation - the guideline development team recommends the use of the assessment procedure described in the practice guideline to evaluate PFM function (level 2)

- Functional examination - the guideline development team recommends that breathing patterns, postural control, voiding posture, and toileting behavior be examined in relation to functioning of PFM (level 3)

- PRAFAB questionnaire - the guideline development team recommends using the PRAFAB questionnaire to assess changes in the patient's health status and the effect of physical therapy intervention (level 1)

- Quantifying the loss of urine - the guideline development team recommends quantifying the loss of urine using the 24-h pad test in case of uncertainty about the quantities of urine being lost (level 3)

- Patient-Specific Complaints (PSC) - the guideline development team recommends using the PSC both to identify the health problem and to evaluate the effect of treatment (level 2)

- Global Perceived Effect (GPE) - the guideline development team recommends using the GPE to evaluate the health status improvement perceived by the patient (level 2) 
- Micturition diary - the guideline development team recommends having patients keep a micturition diary in order to identify the severity of the loss of urine and to evaluate the results of treatment (level 1)

3. Therapeutic process

- Information and advice - the guideline development team recommends the use of anatomical plates and pelvic phantoms, as well as other educational materials such as lifestyle advice (level 4)

- Improving general physical condition - the guideline development team recommends the inclusion in the treatment plan of interventions to improve the patient's general physical condition (level 4)

- Frequency and performance of PFMT - the guideline development team recommends treating SUI by means of daily PFMT with sufficient intensity and duration while paying attention to the correct performance of the exercises and integrating the exercises into activities of daily life (level 1)

- Selective contraction of PFM - the guideline development team recommends combining PFM exercises with electrostimulation in patients who are unable to voluntarily and/or selectively contract their PFM (level 3)

4. Prevention

- PFM training to promote postoperative recovery after prostatectomy - the guideline development team recommends preoperative PFM training for men who have to undergo prostatectomy (level 2)

\section{Conflicts of interest None.}

Open Access This article is distributed under the terms of the Creative Commons Attribution License which permits any use, distribution, and reproduction in any medium, provided the original author(s) and the source are credited.

\section{References}

1. Hannestad YS, Rortveit G, Sandvik H, Hunskaar S (2000) A community-based epidemiological survey of female urinary incontinence: the Norwegian EPINCONT study. Epidemiology of Incontinence in the County of Nord-Trondelag. J Clin Epidemiol 53(11):1150-1157

2. Hunskaar S, Lose G, Sykes D, Voss S (2004) The prevalence of urinary incontinence in women in four European countries. BJU Int 93(3):324-330

3. Dolan LM, Walsh D, Hamilton S, Marshall K, Thompson K, Ashe RG (2004) A study of quality of life in primigravidae with urinary incontinence. Int Urogynecol J Pelvic Floor Dysfunct 15(3):160-164
4. Chong EC, Khan AA, Anger JT (2011) The financial burden of stress urinary incontinence among women in the United States. Curr Urol Rep 12(5):358-362

5. Coyne KS, Kvasz M, Ireland AM, Milsom I, Kopp ZS, Chapple CR (2012) Urinary incontinence and its relationship to mental health and health-related quality of life in men and women in Sweden, the United Kingdom, and the United States. Eur Urol 61(1):88-95

6. Bernards ATM, Berghmans LCM, van Heeswijk-Faase IC, WesterikVerschuuren EHML, de Gee-de Ridder I, Groot JAM et al. (2011) KNGF Guideline for Physical Therapy in patients with Stress urinary incontinence. Dutch Journal of Physical Therapy [121(3 Supplement) Available from: URL:http://www.fysionet-evidencebased.nl/index. php/kngf-guidelines-in-english

7. Haylen BT, de Ridder D, Freeman RM, Swift SE, Berghmans B, Lee $\mathrm{J}$ et al (2010) An International Urogynecological Association (IUGA)/International Continence Society (ICS) joint report on the terminology for female pelvic floor dysfunction. Int Urogynecol J 21: $5-26$

8. WHO FIC Collaborating Centre in the Netherlands, RIVM Bilthoven (2002) Nederlandse vertaling van de WHO-publicatie: International Classification of Functioning, Disability and Health: ICF, Geneva 2001. Bohn Stafleu Van Loghum, Houten

9. Ashton-Miller JA, DeLancey JO (2007) Functional anatomy of the female pelvic floor. Ann N Y Acad Sci 1101:266-296, Epub;\%2007 Apr 7.:266-296

10. Koelbl H, Mostwin J, Boiteux JP, Macarak E, Petri E, Schafer W et al (2002) Pathophysiology. In: Abrams P, Cardozo L, Khoury S, Wein A (eds) International consultation on incontinence book. The International Continence Society, Plymouth, pp 17-82

11. CBO (2007) Evidence-based Richtlijnontwikkeling. Handleiding voor werkgroepleden. Kwaliteitsinstituut voor de Gezondheidszorg CBO, Utrecht

12. Staskin D, Hilton P, Emmanuel A, Goode P, Mills I, Shull B et al (2005) Initial assesment of incontinence. In: Abrams P, Cardozo L, Khoury R, Wein A (eds) Incontinence 3rd international consultation on incontinence. Health Publication Ltd, Plymouth, pp 485-517

13. Lagro-Jansen ALM, Breedveldt Boer HP, van Dongen JJAM, Lemain TJJ, Teunissen D, Van Pinxteren B (2006) NHG-standaard incontinentie voor urine. Huisarts Wetensch 49(10):501-510

14. Brown JS, Bradley CS, Subak LL, Richter HE, Kraus SR, Brubaker L et al (2006) The sensitivity and specificity of a simple test to distinguish between urge and stress urinary incontinence. Ann Intern Med 144(10): 715-723

15. Cameron LD, Leventhal H (2003) The self-regulation of health and illness behaviour. Routledge, London

16. Slieker-ten Hove MC, Pool-Goudzwaard AL, Eijkemans MJ, SteegersTheunissen RP, Burger CW, Vierhout ME (2009) Face validity and reliability of the first digital assessment scheme of pelvic floor muscle function conform the new standardized terminology of the International Continence Society. Neurourol Urodyn 28(4):295-300

17. Messelink B, Benson T, Berghmans B, Bo K, Corcos J, Fowler C et al (2005) Standardization of terminology of pelvic floor muscle function and dysfunction: report from the pelvic floor clinical assessment group of the International Continence Society. Neurourol Urodyn 24(4):374-380

18. Hodges PW, Gandevia SC (2000) Changes in intra-abdominal pressure during postural and respiratory activation of the human diaphragm. J Appl Physiol 89(3):967-976

19. Sapsford RR, Hodges PW, Richardson CA, Cooper DH, Markwell SJ, Jull GA (2001) Co-activation of the abdominal and pelvic floor muscles during voluntary exercises. Neurourol Urodyn 20(1):31-42

20. Hodges PW, Sapsford R, Pengel LH (2007) Postural and respiratory functions of the pelvic floor muscles. Neurourol Urodyn 26(3):362371 
21. Smith MD, Russell A, Hodges PW (2006) Disorders of breathing and continence have a stronger association with back pain than obesity and physical activity. Aust J Physiother 52(1):11-16

22. Versprille-Fischer ES (2001) Begeleiding van patiënten met bekkenbodemdysfunctie. Elsevier Gezondheidszorg, Maarssen

23. Pool-Goudzwaard AL, Slieker ten Hove MC, Vierhout ME, Mulder PH, Pool JJ, Snijders CJ et al (2005) Relations between pregnancyrelated low back pain, pelvic floor activity and pelvic floor dysfunction. Int Urogynecol J Pelvic Floor Dysfunct 16(6):468-474

24. Townsend MK, Danforth KN, Rosner B, Curhan GC, Resnick NM, Grodstein F (2007) Body mass index, weight gain, and incident urinary incontinence in middle-aged women. Obstet Gynecol 110(2 Pt 1):346-353

25. Hendriks EJ, Bernards AT, Staal JB, de Vet HC, de Bie RA (2008) Factorial validity and internal consistency of the PRAFAB questionnaire in women with stress urinary incontinence. BMC Urol 8(1):1

26. Hendriks EJM, Bernards ATM, de Bie RA, de Vet HCW (2008) The minimally important change of the PRAFAB questionnaire in women with stress urinary incontinence: results from a prospective cohort study. Neurourol Urodyn 27(5):379-387

27. Groutz A, Blaivas JG, Chaikin DC, Resnick NM, Engleman K, Anzalone D et al (2000) Noninvasive outcome measures of urinary incontinence and lower urinary tract symptoms: a multicenter study of micturition diary and pad tests. J Urol 164(3 Pt 1):698-701

28. Beurskens AJ, de Vet HC, Koke AJ, Lindeman E, van der Heijden GJ, Regtop W et al (1999) A patient-specific approach for measuring functional status in low back pain. J Manipulative Physiol Ther 22(3): 144-148

29. Hendriks EJ, Bernards AT, Berghmans BC, de Bie RA (2007) The psychometric properties of the PRAFAB-questionnaire: A brief assessment questionnaire to evaluate severity of urinary incontinence in women. Neurourol Urodyn

30. Jaeschke R, Singer J, Guyatt GH (1989) Measurement of health status. Ascertaining the minimal clinically important difference. Control Clin Trials 10(4):407-415

31. Brown JS, McNaughton KS, Wyman JF, Burgio KL, Harkaway R, Bergner D et al (2003) Measurement characteristics of a voiding diary for use by men and women with overactive bladder. Urology 61(4):802-809

32. Averink M, Melein L, Duker PC (2005) Establishing diurnal bladder control with the response restriction method: extended study on its effectiveness. Res Dev Disabil 26(2):143-151

33. Hendriks EJ, Kessels AG, de Vet HC, Bernards AT, de Bie RA (2010) Prognostic indicators of poor short-term outcome of physiotherapy intervention in women with stress urinary incontinence. Neurourol Urodyn 29(3):336-343

34. Alewijnse D, Mesters I, Metsemakers J, van den Borne B (2007) Strategies to enhanse adherence and reduce drop out in conservative treatment. In: Bo K, Berghmans B, Møkved S, Van Kampen M (eds) Evidence based physical therapy for the pelvic Floor. Bridging science and clinical practice. Butterworth Heinemann Elsevier, Edinburgh, pp 133-146

35. Townsend MK, Curhan GC, Resnick NM, Grodstein F (2008) BMI, waist circumference, and incident urinary incontinence in older women. Obesity (Silver Spring) 16(4):881-886
36. Danforth KN, Shah AD, Townsend MK, Lifford KL, Curhan GC, Resnick NM et al (2007) Physical activity and urinary incontinence among healthy, older women. Obstet Gynecol 109(3):721-727

37. Neumann PB, Grimmer KA, Deenadayalan Y (2006) Pelvic floor muscle training and adjunctive therapies for the treatment of stress urinary incontinence in women: a systematic review. BMC Womens Health 6(11):11

38. Moore K, Dumoulin C, Bradley CS, Burgio K, Champion D, Hagen $S$ et al (2012) Adult conservative management. In: Abrams P, Cardozo L, Khoury R, Wein A (eds) Incontinence 5rd international consultation on incontinence. Health Publication Ltd, Plymouth, pp 3-127

39. Haddow G, Watts R, Robertson J (2005) Effectiveness of a pelvic floor muscle exercise program on urinary incontinence following childbirth. Systematic Review. Int $\mathrm{J}$ Evid Based Healthc 3:103-146

40. Glazener CM, Herbison GP, Wilson PD, MacArthur C, Lang GD, Gee $\mathrm{H}$ et al (2001) Conservative management of persistent postnatal urinary and faecal incontinence: randomised controlled trial. BMJ 323(7313):593-596

41. Reilly ET, Freeman RM, Waterfield MR, Waterfield AE, Steggles P, Pedlar F (2002) Prevention of postpartum stress incontinence in primigravidae with increased bladder neck mobility: a randomised controlled trial of antenatal pelvic floor exercises. BJOG 109(1):6876

42. Hunskaar S (2008) A systematic review of overweight and obesity as risk factors and targets for clinical intervention for urinary incontinence in women. Neurourol Urodyn 27(8):749-757

43. Schwartz G, Beatty J (1977) Biofeedback: theory and research. Academic Press, New York

44. Hay-Smith EJ, Bo K, Berghmans LC, Hendriks HJ, de Bie RA, van Waalwijk van Doorn ES (2001) Pelvic floor muscle training for urinary incontinence in women. Cochrane Database Syst Rev 1:CD001407

45. Bo K, Berghmans B, Møkved S, Van Kampen M (2007) Evidence based physical therapy for the pelvic Floor. Bridging science and clinical practice. Butterworth Heinemann Elsevier, Edinburgh

46. Bo K (2012) Pelvic floor muscle training in treatment of female stress urinary incontinence, pelvic organ prolapse and sexual dysfunction. World J Urol 30(4):437-443

47. Berghmans LCM, Hendriks HJ, Bo K, Hay-Smith EJ, de Bie RA, van Waalwijk van Doorn ES (1998) Conservative treatment of stress urinary incontinence in women: a systematic review of randomized clinical trials. Br J Urol 82(2):181-191

48. Hendriks HJM, Bekkering GE, van Ettekoven H, Brandsma JW, van der Wees PJ, de Bie RA (2000) Development and implementation of national practice guidelines: a prospect for continuous quality improvement in physiotherapy. Introduction to the method of guideline development. Physioth 86:535-547

49. Hendriks HJM, Oostendorp RAB, Bernards ATM, van Ravensberg CD, Heerkens YF, Nelson RM (2000) The diagnostic process and indication for physiotherapy: a prerequisite for treatment and outcome evaluation. Phys Ther Rev 5(1):29-47

50. Woolf SH, Grol R, Hutchinson A, Eccles M, Grimshaw J (1999) Clinical guidelines: potential benefits, limitations, and harms of clinical guidelines. BMJ 318(7182):527-530 